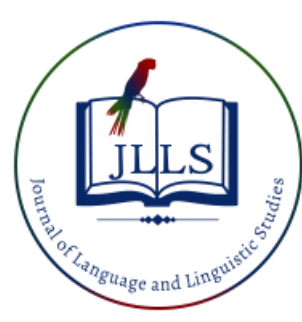

Available online at www.jlls.org

JOURNAL OF LANGUAGE AND LINGUISTIC STUDIES

ISSN: 1305-578X

Journal of Language and Linguistic Studies, 17(4), 1669-1683; 2021

\title{
Descriptive language of 'Thai SELECT Premium' restaurant menus: Appealing perception and collocations
}

\author{
Piyada Low ${ }^{\text {a } 1}$ iD \\ ${ }^{a}$ Kasetsart University Sriracha Campus, Chonburi, Thailand
}

\section{APA Citation:}

Low, P. (2021). Descriptive language of 'Thai SELECT Premium' restaurant menus: Appealing perception and collocations. Journal of Language and Linguistic Studies, 17(4), 1669-1683. Doi: 10.52462/jlls.122

Submission Date:17/04/2021

Acceptance Date:24/06/2021

\begin{abstract}
The study examined menu descriptions of Thai restaurants on how appealing the menus communicated with customers. Data were taken from restaurant websites with 'Thai SELECT Premium' certifications in the UK. 673 menu items were obtained and analyzed in five categories (nationalism, characteristics, sensory cues, branding, organic and healthy concerns). Sensory cues category was mostly used (68.95\%) followed by characteristics (41.9\%) and nationalism 17.53\%). Six Thai dishes on CNN Travel World's 50 Best Foods list in 2011 were investigated on appealing perception of menu descriptions via online questionnaire. Of the six dishes, there were 51 menu descriptions, and 26 descriptions were rated as 'much appealing'. Nationalism (20/26) was mostly found followed by sensory cues (16/26). Menu data were also analyzed by AntConc to extract the high frequency keywords and collocation patterns. Mostly found noun keywords were seven (sauce, chicken, curry, chilli, rice, prawns, and beef) and mostly found adjective keywords were four (sweet, green, red, and spicy). The most frequent collocation patterns were 'noun + noun' and 'adjective + noun'. Respondents requested short and precise menu descriptions, information of food ingredients to help in decision making, and local Thai food names either in Thai words or English transliteration to create exotic experience and to imply the originality.
\end{abstract}

Keywords: Appealing perception; collocation; food names; menu descriptions; Thai restaurant menus

\section{Introduction}

Language takes an important role in convincing consumers to buy a certain product. The use of certain types of language to communicate with the prospect customers helps promote the products. Risko and Wiwczaroski (2014) pointed out that language was a marketing key for the product to be made and sold in the same culture or the product to be made in one place and sold in another place or across the world. Language with information and in current trends will win over the most consumers and lead to the best business outcomes (Pryzant et al, 2017). Product description is important for customers. Informational labelling can influence the customers' decision making and is a means of shaping consumers' knowledge (Caswell and Mojduszka, 1995). Product descriptions are important determinants for consumers (Pryzant et al, 2017).

\footnotetext{
${ }^{1}$ Corresponding author.

E-mail address: fmspyl@ku.ac.th
} 
For restaurant business, menus not only show food and beverage lists but also the images of the restaurants; therefore, food menus are the core of food and beverage operations (Ninemeier, 1990, p. 103; Ozdemir \& Caliskan, 2013; Rosalin \& Soetanto, 2006). They are also marketing tools and can create customers' first impression of a restaurant and expectations on food and beverage (Baiomy et al., 2013; Ninemeier, 1990, p. 103; Omar et al., 2018; Ozdemir \& Caliskan, 2013; Rosalin \& Soetanto, 2006; Tešanović et al., 2016;). Menu is created for communication; therefore, words must be selected to be fascinating and unforgettable (Omar et al., 2018). Menu descriptions help upgrade restaurant images and the perception of value (Wansink et al., 2005). According to Baiomy et al. (2013), menu description factor is an essential dimension of menu marketing, and fine dining restaurants mostly presented individual menus items with descriptive details. Moreover, the availability of online menus can be an effective promotional tool and make an advantage in reaching prospective customers to compete with others. (Ozdemir \& Caliskan, 2013).

A well-designed menu reflects the restaurant's image and is a map for customers to satisfy and enhance their appetites (Omar et al., 2018). The menu must convey the right message to the guests (Ninemeier, 1990, p. 103). Descriptive menu language can influence sales, make the customer believe the food tastes good, and affect customers' behaviors and decisions (Baiomy et al, 2013; Caswell and Mojduszka, 1995; Pryzant et al, 2017; Risko and Wiwczaroski, 2014; Swahn et al, 2012; Wansink et al, 2001; Yang and Lee, 2019). The sales can start from the sight of food description. Customers may choose to dine at a certain restaurant after reading the food descriptions which lead to their expectations of the restaurant service; moreover, descriptive menu names can increase sensory perceptions of appearance and taste as they have influences on food sales, restaurant attitudes, and repurchase intentions (Baiomy et al., 2013; Wansink et al., 2005). Therefore, menu descriptions not only give information but also lead to customers' first-time consumption. Apart from the tastes of the food dishes, elements or ingredients of the food items related to nutritional information are of importance and expected by consumers (Josiam et al., 2012; Musiker and Kesa, 2014; Norrina Din et al., 2012). Lower fat menu items will be of interest for customers with health concern to support the restaurants.

The increase of Thai food production and how Thailand has become a global producer to feed the world market was emphasized by Murray, E.V. (2007). The fresh ingredients and high nutritional value are mentioned as uniqueness of Thai food and enhance the reputation of Thai cuisine as one of the best in the world. Murray also mentioned the importance of 'Thai SELECT' label which is awarded by Department of Business Development of Thailand to qualified Thai restaurants. The label helps standardize Thai restaurants and symbolize high quality Thai restaurant service. The certification of Thai SELECT restaurant as explained on its webpage (thaiselect.com) is for the two categories: decoration and service excellence. Authentic Thai restaurants will be awarded Thai SELECT for "a degree of excellence of 3 to 4-stars" and Thai SELECT Premium for "a degree of excellence of 5-star or higher". The restaurants "serving authentic Thai food with premium quality in luxury decorations and outstanding services" can be granted the label. The validity and renewal of Thai SELECT seal is three years.

Academic research studies on descriptive menu language have been conducted with western dishes and Asian cuisines, but not particularly with Thai cuisine. The present study; therefore, focuses on the menus of Thai restaurants, especially the restaurants with Thai SELECT Premium certificates to examine the types of menu descriptions communicating with the prospect customers, and to investigate the appealing perception of these menu descriptive language.

In term of language, collocation of menu description is also explored to aware of the constraints on word combinations in English (Boonyasaquan, 2005; Donnellan, 2014; Moehkardi, 2002). The knowledge of collocation use can improve second language proficiency. Moreover, using vocabulary 
correctly and appropriately in natural contexts is relatively difficult for EFL/ESL learners. Language learners need to know how to use vocabulary in different contexts. As for the phrase "fast food", it cannot say "quick food" as it is not natural in English language (Choi, 2017). Buakaew (2015) explained that an English word did not usually have only one meaning, but its meaning could change when it was an idiomatic expression; therefore, the teaching of collocation should be a top priority in every language course. Collocations should be introduced to students at the earliest possible stage of language learning (Boonyasaquan, 2005) with the highest frequency ESP language elements (Jendrych, 2013). For Alotaibi and Alotaibi (2015), choosing words carefully in specific situations is more necessary than choosing grammatical structures. Bahns (1993) pointed out that lack of collocational competence leads to errors in choosing the correct combination of two (or more) words. In Thai language, the word 'perd - เปิด' means to open, to switch on, to start, and can be directly translated as 'open' such as 'open the door'. Therefore, an error in Thai context might produce 'to open the light' instead of 'to turn on the light' (Boonyasaquan, 2005). For Salmani Nodoushan (2011), the knowledge of corpus linguistics helps share the insights of ESP to develop a comprehensive picture of the nature of English writing in international communication.

There are three objectives in the present study as follows:

Objective 1. To examine types of menu description of 'Thai SELECT Premium' restaurants

Objective 2: To study the appealing perception of descriptive menu language

Objective 3: To identify the keywords and the most frequent collocation patterns in descriptive menu language

\subsection{Literature review}

Research studies concerning the use of product description are as follows.

Wansink et al (2001) conducted a research study and believed that menu description would increase sales and enhance food quality perceptions. The experiment was conducted in a faculty cafeteria at the University of Illinois. They found that 56 percent of the customers chose the menu items with descriptions and concluded that menu description was important in deciding. The questionnaire results showed that with product description, their sales increased by 27 percent. Menu descriptions help encourage consumption and continuous sales. The researchers suggested that restaurant managers should check the use of menu descriptions and revitalize the menus to meet customers' expectations. The four themes to revitalize menus proposed by Wansink et al (2001) are Geographic Labels which emphasizes on the place or region of the products; Affective Labels which emphasizes on family, tradition, and nationalism; Sensory Labels; and Brand Labels.

Baiomy et al (2013) believed that menus were vital marketing tools, made guests' first impression, and raised guests' expectation of the food menu items. The online menus of 36 resort hotels were analyzed. The menus were analyzed according to the complexity of the description with six considerations: "Level of complexity of a menu description; Sense of Place (SoP) including local language or the language related to the cuisine; Use of local foods, organic foods, or in combination as local and organic foods; Sensory or affective wording; Provenance of menu items including the place of origin of the food product as well as a method of preparation or service: and Use of branding."

Pryzant et al (2017) conducted a research study with the belief that textual product descriptions were important determinants of consumer choice. 93,591 product descriptions and sales records from the Japanese e-commerce website rakuten.co.jp were examined. The data were on two products categories: chocolate and health. The analysis of influential words used in product descriptions falls into four categories: Informativeness which includes logos, brand names, or product names with 
structured information and detail; Authority which includes authoritative figures or long-standing tradition; Seasonality which suggests seasonal dependencies; and Politeness which expressions show politeness, respectfulness, and humbleness.

Tešanović et al. (2016) proposed that descriptive names of food menus were more appealing than classical names. Participants were asked to rate the menus as the most appealing (5), average appeal (4), neither appealing nor unappealing (3), partially appealing (2), and the least appealing (1). The results showed that menu labels with the organic/healthy safe labels were the most appealing, followed by the sentimental labels, the authentic labels, and the national labels. The researchers explained that because of the growing health concern, description of organic/healthy safe labels were; therefore, marked as the most appealing.

McCall and Lynn (2008) conducted a survey on food preference and restaurant behavior with 160 college students. Three dishes of beef, chicken, and pasta were determined for the complexity of descriptions. The menu items which were described in more complex terms could increase perceptions of quality, likely choice, and pricing expectations. This finding is in line with Wansink et al. (2001) and Pryzant et al. (2017).

A case study was conducted with Dutch people at a fine dining restaurant by Rosalin and Soetanto (2006). The restaurant provides the combination of Thai, Malaysian, and Chinese cuisines. More than half of the respondents (68\%) visited the restaurant at least once a month. Menu variety was mentioned as the most influencing factor to dine at the restaurant. In terms of food characteristics, the researchers pointed out that sensory properties played an important role. Color, texture and shape, consistency, flavor, method of preparation, serving temperature, and presentation are parts of the sensory properties. Research findings showed that ingredients were the most influencing factor in choosing a dish $(86 \%)$, and the guests perceived that more vegetables and fruits indicating healthy eating (52\%); however, vegetarian dish was the least preferable $(82 \%)$. For the taste preference, sweet-sour was the most preferable (34\%) followed by spicy taste (30\%).

Research studies related to customers' satisfaction of restaurants in Thailand gave the importance on food quality (Boonpalit, 2018; Jaidee, 2010; Lasitamas, 2016; Singsomboon, 2015). Singsomboon (2015) pointed out that Thai food knowledge could be used as marketing strategy to promote tourism business in Thailand, and proposed that Thai food must have one of 9 characteristics: (1) ingredients firstly found in Thailand; (2) unique Thai cooking methods; (3) Thai geography; (4)Thai ethnic group and culture, (5) popularity across the country; (6) first entry recorded by Thai ethnic group; (7) tradition, culture, and custom known with historical evidence; (8) local ingredients of the previous Thai kingdom; and (9) being internationally accepted as Thai food.

Buakaew (2015) explored 300 words of collocations in food and beverage advertisements from the Bangkok Post and the Internet. Lexical collocations were found more frequently than grammatical collocations. "Adjective + noun" type of lexical collocations was found as the most frequently used in food and beverage advertisements. The finding was confirmed by Pryzant et al. (2017) who found a great number of adjectives and adverbs in their influential word lists and explained that adjectives and adverbs could be indicative of informativeness. The same collocation pattern of 'Adjective + noun' was also found in the research study on collocations in facial skincare product online advertisements by Lakkam (2017). The findings revealed that there were seven types of lexical collocations used in skincare product online advertisements. The most frequent lexical collocation type used in skincare product online is Adjective + Noun collocation pattern. The researcher pointed out that adjectives could describe fact and opinion meaning to persuade customers. 


\subsection{Research questions}

There are three research questions.

Question 1: What types of descriptions do the menus of 'Thai SELECT Premium' restaurants communicate with the prospective customers?

Question 2: Which descriptive menu language can create the appealing perception?

Question 3: Which keyword and types of collocation patterns are mostly used in descriptive menu language of 'Thai SELECT Premium' restaurants?

\section{Method}

\subsection{Data collection}

The first data were authentic materials taken from food menus of the restaurant websites with 'Thai SELECT Premium' certifications in the United Kingdom.

There were 43 Thai restaurants awarded as Thai SELECT Premium from the Department of International Trade Promotion in the United Kingdom on the Thai SELECT webpage: www.thaiselect.com. However, two Thai restaurants were not available with online menus, and three Thai restaurants had been closed. There were five Thai restaurant names with branches namely Chaophraya ( 7 branches), Patara Fine Thai Cuisine (6 branches), Thai Square (13 branches), Thaikhun ( 2 branches), and Koh Thai Tapas ( 6 branches). These restaurants provided the same food menus in their branches. There were five individual Thai restaurants available with online menus (Sabai Thai Gastrobar, Thai Tho, Rumwong, Mango Tree, and Nipa). The total number of the Thai SELECT Premium restaurants for the present study; therefore, was 10 .

The second data were from the online questionnaire consisting of two types: closed questions (check-list and rating scales) and open-ended questions. The online questionnaire was distributed via fellow lecturers, acquaintances, and friends. Timeframe for collecting the online questionnaire data was two months during May and June 2020. The data of menu descriptions were analyzed and classified for frequency word list, keywords, and collocations.

\subsection{Instruments}

Three types of research instruments were employed in the study to answer the three research objectives and three research questions.

1. The five categories of menu descriptions were derived from the reviewed research studies (Baiomy et al, 2013; Pryzant et al, 2017; Singsomboon, 2015; Tešanović et al, 2016; Wansink et al, 2001). Similar proposals were put into one category; therefore, the food menu descriptions could be analysed according to the following five categories:

1). Nationalism. This includes local language or language related to the cuisine and the use of Thai food menu names.

2). Characteristics. This includes the use of words related to the uniqueness of Thai cuisine, cooking styles and ingredients as well as the names of the original place of the food menu items.

3). Sensory cues. This includes five senses: sight, taste, smell, sound, touch, or texture.

4). Branding. This includes informativeness or logos of the restaurants and the use of branded menu items. 
5). Organic and healthy concerns with the use of local foods, organic foods, or in combination as local and organic foods.

2. The online questionnaire was employed to investigate the appealing perception of descriptive menu language according to the five categories of menu descriptions. The seven Thai dishes announced on CNN Travel World's 50 Best Foods list in 2011 were rated using a scale of 1 (not appealing) to 5 (most appealing). The seven Thai dishes were Tom Yum Kung, Pad Thai, Som Tum, Massaman, Green Curry, Chicken Fried Rice, and Mu Nam Tok.

Three experts were invited to validate the content validity of the questionnaire. The experts consisted of two doctoral degree lecturers in the culinary field and hospitality, and a doctoral degree lecturer of English language. The questionnaire consisted of two types of questions: close-ended (checklist) and open-ended (rating scales).

3. A corpus analysis program named Anthony's AntConc (3.5.8) was used to investigate high frequency word list, keywords, and collocation patterns of the descriptive menu language of Thai restaurants.

\subsection{Data analysis}

The restaurant menus were downloaded and saved as 10 files of Word documents according to the restaurant names: Chaophraya, Koh Thai Tapas, Mango Tree, Nipa, Patara Fine Thai Cuisine, Rumwong, Sabai Thai Gastrobar, Thaikhun, Thai Square, and Thai Tho. The total number of all restaurant menu items was 673 . The menu items then were analyzed according to the five categories of menu descriptions. The items were also extracted for high frequency word list, keywords, and collocations by AntConc (3.5.8).

Among the seven Thai dishes selected for appealing perception analysis, only six dishes were available from the ten Thai restaurants. Mu Nam Tok or spicy minced pork salad was not on the menus of the ten restaurants. Moreover, some dishes were not available in all restaurants. Four menu items were available in all 10 restaurants $(4 \times 10=40)$. Massaman menu item was available in 9 restaurants $(1 \times 9=9)$, and chicken fried rice menu was available in two restaurants $(1 \times 2=2)$. Therefore, the number of food menu items using on the scale of 1 (not appealing) to 5 (most appealing) was 51 .

\section{Results}

Results were presented in three parts according to the three objectives and three research questions.

\subsection{Restaurant menu data are shown according to Objective 1 and Question 1.}

Objective 1. To examine types of menu description of 'Thai SELECT Premium' restaurants

Question 1: What types of descriptions do the menus of 'Thai SELECT Premium' restaurants communicate with the prospective customers?

Of the ten restaurants, only 'Mango Tree' restaurant was available with Thai words of all menu items. 'Nipa' was the only Thai restaurant presenting all menu items with English transliteration. Four Thai restaurants presented some of their menu items with English transliterations: Koh Thai Tapas (11.94\%), Thaikhun (25\%), Patara Fine Thai Cuisine (27.27\%), and Thai Square (34.85\%). The food menu items were presented with English transliteration at $67.46 \%$. On the contrary, English menu descriptions were presented with all food menu items (100\%). The uses of English transliteration and English descriptions of food menu items were shown in table 1. 
Table 1. English transliteration and English descriptions of Thai food menu items

\begin{tabular}{|c|c|c|c|c|c|}
\hline Restaurants & No. of menu items & English transliteration & $\%$ & $\begin{array}{l}\text { English } \\
\text { description }\end{array}$ & $\%$ \\
\hline Chaophraya & 80 & 77 & 96.10 & 80 & 100 \\
\hline Koh Thai Tapas & 67 & 8 & 11.94 & 67 & 100 \\
\hline Mango Tree & 68 & 50 & 73.53 & 68 & 100 \\
\hline Nipa & 46 & 46 & 100 & 46 & 100 \\
\hline Patara Fine Thai Cuisine & 44 & 12 & 27.27 & 44 & 100 \\
\hline Rumwong & 119 & 117 & 98.32 & 119 & 100 \\
\hline Sabai Thai Gastrobar & 68 & 54 & 79.41 & 68 & 100 \\
\hline Thaikhun & 32 & 8 & 25 & 32 & 100 \\
\hline Thai Square & 66 & 23 & 34.85 & 66 & 100 \\
\hline Thai Tho & 86 & 62 & 72.09 & 86 & 100 \\
\hline Total & 673 & 454 & 67.46 & 673 & 100 \\
\hline
\end{tabular}

All 673 food menu items were analyzed in five categories of menu descriptions and presented in table 2 .

Table 2. Descriptive menu language in five categories

\begin{tabular}{|c|c|c|c|c|c|c|c|c|c|c|c|}
\hline \multirow[t]{2}{*}{ Restaurants } & \multirow[t]{2}{*}{$\begin{array}{l}\text { No. } \\
\text { menu } \\
\text { items }\end{array}$} & ffNati & alism & Char & eristics & Sens & ry Cues & Bran & ing & \multicolumn{2}{|c|}{$\begin{array}{l}\text { Organic } \\
\text { Healthy } \\
\text { concerns }\end{array}$} \\
\hline & & $\mathrm{No}$ & $\%$ & No & $\%$ & No & $\%$ & No & $\%$ & No & $\%$ \\
\hline Chaophraya & 80 & 11 & 13.75 & 58 & 72.5 & 57 & 71.25 & 11 & 13.75 & 7 & 8.75 \\
\hline Koh Thai Tapas & 67 & 1 & 1.49 & 38 & 56.72 & 52 & 77.62 & 12 & 17.91 & 1 & 1.49 \\
\hline Mango Tree & 68 & 67 & 98.53 & 42 & 61.76 & 49 & 72.06 & 5 & 7.35 & 1 & 1.47 \\
\hline Nipa & 46 & 1 & 2.17 & 9 & 19.57 & 28 & 60.87 & - & 0 & 1 & 2.17 \\
\hline Patara & 44 & 1 & 2.27 & 9 & 20.45 & 38 & 86.36 & 1 & 2.27 & 2 & 4.55 \\
\hline Rumwong & 119 & 6 & 5.04 & 30 & 25.21 & 93 & 78.15 & 6 & 5.04 & 4 & 3.36 \\
\hline Sabai Thai & 68 & 10 & 14.71 & 34 & 50 & 51 & 75 & 6 & 8.82 & 33 & 48.53 \\
\hline Thaikhun & 32 & 6 & 18.75 & 23 & 71.88 & 24 & 75 & 4 & 12.5 & 3 & 9.38 \\
\hline Thai Square & 66 & 4 & 6.06 & 27 & 40.91 & 29 & 43.94 & 5 & 7.58 & 1 & 1.52 \\
\hline Thai Tho & 86 & 6 & 6.98 & 12 & 13.95 & 43 & 50 & 1 & 1.16 & 1 & 1.16 \\
\hline Total & 673 & 118 & 17.53 & 282 & 41.9 & 464 & 68.95 & 51 & 7.58 & 51 & 7.58 \\
\hline
\end{tabular}


Of the five categories, sensory cues category was the most used (68.95\%) followed by characteristics (41.9\%), and nationalism (17.53\%). However, nationalism (98.53\%) was used most in Mango Tree and characteristics (72.5\%) was used most in Chaophraya.

Examples: Sensory cues

- Fresh Rice Roll, A choice of prawn (9.50) vegetable (8.20)

Refreshing, thin strips of vegetables \& mint hand-rolled in rice paper with a chilli and lime dressing (Patara Fine Thai Cuisine)

- Gung Grabuang

Crispy crape filled with a blend of prawns, coriander and fresh herbs, served with sweet chilli sauce (Rumwong)

Examples: Nationalism

- ไก่ย่าง Gai Yang Jerapan

Grilled boneless corn-fed chicken southern style marinated in coconut milk and Thai herbs. Served with spicy nam jim jaew sauce (Mango Tree)

Apart from Thai word 'ไก่ย่า', the word 'nam jim jaew' was an English transliteration of Thai sauce name used to emphasize the nationalism category.

-Kao Niew (Thai Steamed Sticky Rice)

Thai's eat this with their fingers! Making it into balls and eating with dishes like Larb and Som Tum (Sabai Thai Gastrobar)

Examples: Characteristics

-Grilled Pork Skewers

King of the street! Pork marinated with coconut milk, coriander, garlic, palm sugar and oyster sauce. Served with jaew sauce. Aroy jing jing. (Delicious, trust us!) (Thaikhun).

\subsection{Questionnaire data were presented according to Objective 2 and Question 2.}

Objective 2: To study the appealing perception of descriptive menu language

Question 2: Which descriptive menu language can create the appealing perception?

Of 253 respondents, $164(64.8 \%)$ were female and $89(35.2 \%)$ were male. In term of age duration, $136(53.8 \%)$ were over 40 years, $44(17.4 \%)$ were of 36-40 years, 41 (16.2\%) were of 26-30 years, and $32(12.6 \%)$ were of $20-25$ years. For educational background, respondents with bachelor's degrees were equal to respondents with master's degree at 106 (41.9\%). Respondents with doctoral degrees were 24 (9.5\%), and respondents below bachelor's degrees were17 (6.7\%). Respondents indicated their English usage at different levels: 98(38.7\%) at much level, 96 (37.95\%) at moderate level, 35 $(13.8 \%)$ at most level were and $2(0.8 \%)$ at least level.

For the frequency of restaurant dining, 98 (38.7\%) dined in restaurants 2-3 times a week, 59 (23.3\%)- once a week, 57 (22.5\%)- once a month, $33(13 \%)$ - 2-3 times a month, and 6 respondents (2.4\%) dined in restaurants every day.

For the appealing perception of descriptive menu language, the 51 food menu items were rated on a scale of 1 (not appealing) to 5 (most appealing). The finding showed that there were 26 items rated as 'much appealing'. When these 26 items were compared with the five categories of menu descriptions, nationalism (20/26) was the mostly found category followed by sensory cues (16/26). Characteristics 
(9/26) and branding (2/26) was less found. Organic and healthy concerns $(1 / 26)$ was the least found category in 'much appealing' menu items.

There were 91 respondents wrote in the comment section of the online questionnaire. 24 respondents pointed out that they preferred short and precise menu descriptions. Ingredients and cooking methods were recommended to be shown in menu descriptions in 16 comments. Among these 16 comments, seven comments explained that the shown ingredients helped in decision making, especially people with certain food allergies. The use of local Thai food names was also suggested by 11 respondents. Thai food names in Thai words or English transliteration were suggested to be added with English menu descriptions. The use of local Thai food names was well elaborated by the respondent no. 20 that local names helped create exotic experience of dining, especially for foreigners.

In terms of language use, two comments were on the use of certain words in menu description. The words fell into three categories of menu description: nationalism, characteristics, and sensory cues. The use of these words helped increase the food value. The two comments are as follows:

Comment of respondent no.127 - If using words help customers have pictures of how the dish made deliciously, it would be most interesting. E.g., tossed in, fresh, vibrant, homemade, etc.

Comment of respondent no.152 - In my opinion the word you use for explain the dish is more effect customer to buy, for example if you put the word homemade or original in some of the ingredient it will make the dish more value.

\subsection{Restaurant menu data were analyzed by Ant Conc and shown according to Objective 3 and Question 3.}

Objective 3: To identify the keywords and the most frequent collocation patterns in descriptive menu language

Question 3: Which keyword and types of collocation patterns are mostly used in descriptive menu language of 'Thai SELECT Premium' restaurants?

The ten Word document files of ten Thai restaurant menus were converted to text format (.txt) files so as to be analyzed by Ant Conc. The program showed that there were 12,910 word tokens or total number of words in the corpus of restaurant menu data.

'Word List' function of Ant Conc counted word frequency of the restaurant menu corpus and extracted keywords which were high frequency words in the corpus for further collocation analysis.

Top 20 keywords by frequency of more than 100 occurrence were shown in table 3 .

Table 3. Top 20 keywords of more than 100 frequency occurrence

\begin{tabular}{llllll}
\hline Rank no. & Word & Frequency & Rank no. & Word & Frequency \\
\hline 1 & and & 694 & 11 & chilli & 167 \\
2 & with & 688 & 12 & served & 164 \\
3 & sauce & 294 & 13 & stir & 155 \\
4 & a & 255 & 14 & rice & 149 \\
5 & fried & 227 & 15 & sweet & 135 \\
6 & Thai & 222 & 16 & prawns & 133
\end{tabular}




\begin{tabular}{llllll}
7 & chicken & 209 & 17 & beef & 103 \\
8 & of & 193 & 18 & green & 102 \\
9 & in & 181 & 19 & red & 102 \\
10 & curry & 178 & 20 & spicy & 102 \\
\hline
\end{tabular}

The top 20 keywords were of different types of words: 7 common nouns, 4 adjectives, 3 prepositions, 2 past participles, 1 connector, 1 article, 1 verb, and 1 proper noun. The keywords of nouns, adjectives, prepositions, and past participles were analyzed for the most frequent collocation patterns using the 'collocate' function of Ant Conc.

1) Noun keyword.

The most frequent collocation pattern of noun keyword was noun words before noun keywords (noun + noun). The most used collocation patterns of the noun keyword 'sauce' were chilli sauce, oyster sauce, and soy sauce respectively.

Example:

- Chicken with Cashew Nuts

Gai Pad Met Mamuang Himmapan

A popular traditional dish of stir-fried chicken with cashew nuts, onions, mushrooms, peppers with a roasted red chilli sauce and crispy chilli. (Chaophraya)

2) Adjective keyword.

The adjectives 'red' and 'green' were found with the noun keyword 'curry': red curry and green curry. The sample of the collocation pattern of adjective keyword before noun word is as follows:

Examples:

- Gang Kiew Wan (Green Curry) choose from chicken/ pork/beef/prawns

Green curry past, bamboo shoots, courgetti, carrot and Thai herbs in coconut milk (Sabai Thai Gastrobar)

3) Preposition keyword.

The preposition 'with' keyword was mostly used after the past participle keyword 'served' (past participle + preposition): served with.

Example:

- Gung Tod

Delicious deep-fried prawns marinated in our special blend of herbs and spices, served with chilli sauce (Ramwong)

4) Past participle keyword.

The most frequent collocation pattern of past participle keyword was after the verb 'stir' (verb + past participle): stir-fried, a compound verb.

Examples:

- Phad Kra Prao Koon

Stir-fried prawns with chillies and basil leaves (Nipa)

- Kung Pad Prik 
Stir-fried prawns with baby corn, mushrooms and broccoli (Thai Tho)

The most frequent collocation patterns used in descriptive menu language of 'Thai SELECT Premium' restaurants could be identified and summarized into four collocation patterns: noun + noun, adjective + noun, past participle + preposition, and verb + past participle.

\section{Discussion}

The results are discussed according to the types of menu descriptions, appealing perception, and collocations.

\subsection{Types of Menu Descriptions}

Of the five categories, sensory cues category was the most used in descriptive menu language $(68.95 \%)$. This finding proves that sensory perceptions of appearance and taste should be increased in descriptive menu language as explained by Wansink et al. (2005). The finding emphasized the notion of Tešanović et al. (2016) that dish names with sensory characteristics were more appealing. Rapp (2016) recommended that food ingredients, food category, and taste could include in menu description especially of unfamiliar food. The food menu items were already presented in food categories of the menu, and food ingredients were also mentioned in descriptions; therefore, taste could be added to encounter with unknown food dishes.

Characteristics was the second most used in menu descriptions (41.9\%). The use of region of origin on product could infer favorable taste qualities of the products (Van Ittersum et al. 2003). Stating geographic origin was recommended to add value to the menu item. It made the menu stand on its own with personality (Rapp, 2016).

Branding as well as organic and healthy concerns were the least used (7.58\%). Branding was less important for people who were familiar with the food category as they could still relate the food dishes with their sensory perceptions (Wansink et al., 2005). In term of organic and healthy concerns, Thai food is generally high in nutritional value with fresh ingredients (Murray, 2007). Therefore, the restaurants did not give more emphasis on more details as the food is already considered as 'a healthy and non-fattening diet' (Murray, 2007).

\subsection{Appealing Perception of Descriptive Menu Language}

As the questionnaire data revealed the dominant age group of the respondents as over 40 year (53.8\%), this meant that the respondents were mature and had adequate dining experience. In terms of gender, $64.8 \%$ of respondents were female. Female customers were perceived as more sensitive to services than male customers (Ma, Qu, \& Eliwa, 2014; Muhamad Saufi yudin Omar et al., 2016; Zhong $\&$ Moon, 2020). Among the total respondents, respondents with bachelor's degree and master's degree were equal at $41.9 \%$ followed by doctoral degree holders at $9.5 \%$, and only $6.7 \%$ were below bachelor's degrees. This indicates that most of the respondents were educated and working for living. They would be concerned about their expenses and spending. The finding that $38.7 \%$ of the respondents dined in restaurants 2-3 times a week indicated certain dining experience.

Among the 51 menu items rated for the appealing perception, there were 26 menu items rated as 'much appealing'. Of the 26 items, nationalism (20/26) was the mostly found category of menu descriptions. Lockyer (2006) pointed out that the use of local words helped create good feeling to guests reading a menu. According to Tešanović et al. (2016), food dishes with descriptions related with nation and something authentic have more influence on guests' decision than the classical food 
names. Therefore, nationalism which includes Thai local language and Thai food menu names is rated as 'much appealing'.

The finding that respondents requested food ingredients in menu descriptions was in line with Josiam et al. (2012), Musiker and Kesa (2014), and Norrina Din et al. (2012).

Although Wansink et al. (2001) mentioned that detail description indicated that the menu was of better quality and value, 24 of the total 91 comments preferred short and precise menu descriptions. These comments confirmed the notion that long descriptions could confuse guests (Davis et al., 2008). Rapp (2016) also recommended that long menu descriptions should be used only with most popular and profitable dishes while other dishes should be presented with basic descriptions.

\subsection{Collocations}

Of the top 20 keywords with more than 100 occurrences, there are 7 noun keywords (sauce, chicken, curry, chilli, rice, prawns, and beef) and 4 adjectives (sweet, green, red, and spicy). The finding is in line with Low (2019) that the words 'chilli, curry, spicy, prawn and beef' were categorized as top 20 most frequent specialized vocabulary of Thai cuisine. The dominant keywords of Thai dishes, therefore, are 'curry, chilli, and spicy'.

Chilli is commonly found in various kinds of Thai dishes: snacks; soups; salads; fried dishes; and steamed dishes. Curry was perceived as 'searingly hot' (Rosalin \& Soetanto, 2006) and steamed rice with curry is on daily basis of Thai cuisine from breakfast and lunch to dinner (Low, 2019). The adjective word 'spicy' indicates the taste which is robust in Thai cuisine (Svasti, 2010) and like a signature of Thai dishes (Low, 2019).

Four collocation patterns are the basic of English grammatical structure. The finding of 'adjective + noun' pattern is in line with Buakaew (2015), Lakkam (2017), and Pryzant et al. (2017). The adjective function is to give more information to a noun word, so the use of adjectives can give better image and condition of food dishes such as texture, taste, color, and shape. Lakkam (2017) pointed out that adjectives could help persuade prospect customers.

\section{Conclusions}

The study has shown the types of descriptive menu language of Thai restaurants, especially 'Thai SELECT Premium' restaurants in the UK. The reason of choosing restaurants in the UK, a native English-speaking country, is the implication that these menus can communicate with English native speakers in actual situations of restaurant business. The findings of appealing perception and collocation patterns in menu descriptions can implement the ESP course, especially English for Food and Beverage Service. Collocation pattern, especially 'adjective + noun' should be emphasized to help in writing English menu descriptions naturally and effectively. Food dishes with adjective information such as color, shape, texture, and taste can attract prospect customers, especially if the dishes are unfamiliar. Further research studies are recommended with other types of cuisine to enhance the body of knowledge in the field of ESP course, particularly for food and beverage service and restaurant business.

\section{Acknowledgements}

The research study was fully funded by the Faculty of Management Sciences, Kasetsart University Sriracha Campus, Thailand. 


\section{References}

Anthony, L. (2014). AntConc (Version 3.4.4) [Computer Software]. Tokyo, Japan: Waseda University. from http://www.laurenceanthony.net

Bacon, L., Wise, J., Attwood, S., \& Vennard, D. (2018). The language of sustainable diets: A field study exploring the impact of renaming vegetarian dishes on U.K. cafe menus. Technical Note. Washington, D.C.: World Resources Institute. from: https://wriorg.s3.amazonaws.com/s3fspublic/language-sustainable-diets.pdf.

Bahns, J. (1993). Lexical collocations: A contrastive view. ELT Journal, 47(1), 56-63.

Beauchamp, T. L., \& Childress, J. F. (2013). Principles of biomedical ethics (7th ed.). New York: Oxford University Press.

Benson, M. (1985). Collocations and idioms, in R. Ilson (ed.), Dictionaries, lexicography and language learning. British Council: Pergamon Press.

Boonpalit, A. (2018). Appropriate Marketing Strategy for Restaurants in Bangkok. Journal of Suvarnabhumi Institute of Technology (Humanities and Social Sciences), 4(2), 108-123.

Boonyuasaquan, S. (2005). An Analysis of Collocational Violations in Translation. Journal of Humanities, 27(2), 79-91.

Borden, N.H. (1964). The Concept of the Marketing Mix. Journal of Advertising Research, 4, 2-7.

Buakaew, R. (2015). A Study of Collocation Usage in Food and Beverage Advertisements. Panyapiwat Journal, 7(2), 232-244.

Caswell, J.A. And Mojduszka, E.M. (1995). Using Informational Labeling To Influence the Market for Quality in Food Products. American Journal of Agricultural Economics, 49.

Choi, S. (2017). Processing and learning of enhanced English collocations: An eye movement study. Language Teaching Research, 21(3), 403-426.

Davis B, Lockwood A, Alcott P, Pantelidis, I. (2008). Food and Beverage Management. (4thed), Butterworth-Heinemann, Oxford, UK

Donnellan, M. (2014). An Analysis of Collocations in an Authentic Text. Humanities Review, 19, $227-$ 243.

Froehlich, H. (2015). Corpus analysis with Antconc. Programming Historian. Retrieved from https://programminghistorian.org/lessons/corpus-analysis-with-antconc

Jaidee, D. (2010). Factors Affecting Decision Making of People in Choosing Service of Food Shops in Surat Thani Province. Master Thesis of Business Administration. Graduate School. Suratthani Rajabhat University.

Jendrych, E. (2013). Developments in ESP Teaching. Studies in Logic, Grammar, and Rhetoric, 34(47), 43-58.

Josiam, B.M., Foster, C.R., and Bahulkar, G. (2012). For Whom the Menu Informs: A Market Segmentation Approach to Nutritional Information on Restaurant Menus. Tourismos: An International Multidisciplinary Journal of Tourism, 7(2), 237-259.

Lasitamas, P. (2016). Service Marketing Strategy of Perceived Value for Thai Fusion Food for ASEAN. SDU Research Journal Humanities and Social Sciences, 12(3), 133-145. 
Lakkam, P. (2017). The Lexical Collocations Used in Facial Skincare Product Online Advertisements. Independent Study Paper for Master of Arts in Career English for International Communication. Language Institute. Thammasat University.

Likert, R. (1932). A Technique for the Measurement of Attitudes, Archives of Psychology, No. 140. Paris: The University of Western Ontario.

Lockyer, T. (2006). Would a restaurant menu item by any other name taste as sweet? FIU Hospitality and Tourism Review, 24, 21-31.

Low, P. (2019). Identifying Specialized Vocabulary in Thai Food Menus Using Computer-Based Approach, Journal of Advances in Information Technology, 3(10), 94-91. http://www.jait.us/index.php?m=content $\& c=$ index $\& a=$ show $\&$ catid $=192 \& i d=1066$

Ma, E., Qu, H., \& Eliwa. R.A. (2014). Customer loyalty with fine dining: The moderating role of gender. Journal of Hospitality Marketing \& Management, 23(5), 513-535.

McCall, M. and Lynn, A. (2008). The Effects of Restaurant Menu Item Descriptions on Perceptions of Quality, Price, and Purchase Intention. Journal of Foodservice Business Research, 11(4), 439-445.

Muhamad Saufi yudin Omar et al. (2016). Service Quality, Customers' Satisfaction and the Moderating Effects of Gender: A Study of Arabic Restaurants. Procedia - Social and Behavioral Sciences, 224, 384-392.

Murray, E.V. (2007). Thailand-The Kitchen of the World: Origin and Growth of the Thai Food Industry \& Lessons for India. Cab Calling, April-June, 16-26.

Musiker, J.C. and Kesa, H. (2014). The Impact Nutritional Information Has on Customers' Behaviours towards Their Food Choices in Restaurants. Global Review of Research in Tourism, Hospitality and Leisure Management, 1(1), 34-57.

Ninemeier, J.D. (1990). Management of Food and Beverage Operations, $2^{\text {nd }}$ ed. Lansing, Michigan: Educational Institute American Hotel and Motel Association.

Norrina, D, M.Z. Salehuddin Mohd, and S. Shariff Mohd. (2012). Customer Perception on Nutritional Information in Restaurant Menu. Procedia - Social and Behavioral Sciences, 42, 413 - 421.

Omar A.A. Jawabreh, Taghreed Al Jaffal, Haitham Abdelrazaq, Rami Muneer Mahmoud. (2018). The Impact of Menus on the Customer Satisfaction in Restaurants Classified in Aqaba Special Economic Zone Authority (ASEZA). Journal of Tourism, Hospitality and Sports, 33, 29-39.

Ozdemir, B. and Caliskan, O. (2013). A review of literature on restaurant menus: Specifying the managerial issues. International Journal of Gastronomy and Food Science, 2, 3-13.

Rapp, G. (2016). How to Write Powerful Menu Descriptions That Increase Profits. Menu Cover Depot. Retrieved on 24 July 2019 from https://www.menucoverdepot.com/resourcecenter/articles/how-to-write-menu-descriptions/

Risko, T.C. and Wiwczaroski, T.B. (2014). Integrating Language Learning and Culture into an ESP International Marketing Course Syllabus. English for Specific Purposes World, 43(15).

Salmani Nodoushan, M.A.S. (2011). The place of genre analysis in international communication. International Journal of Language Studies, 5(1), 63-74.

Singsomboon, T. (2015). The Use of Thai Food Knowledge as Marketing Strategies for Tourism Promotion. Thammasat Review, 18(1), 82-98. 
Sirisoontorn, S. (2012). Thai Food Culture...from Past to Present. Bangkok: Office of Printing Mill. The War Veterans Organization of Thailand.

Svasti S. (2010). The principles of Thai cookery. Nonthaburi, Thailand: Mc Dang dot Com Company, Limited, 1-304. ISBN 978-6-16906-010-9

Tešanović, D., Banjac, M., Kalenjuk, B., Radivojević, G. (2016): The impact of the names of dishes on the guest's choice of restaurant food. Singidunum international tourism conference 2016. September 30, 2016, Belgrade, Serbija. ISBN: 978-86-7912-641-2, 169-173.

Van Ittersum, K., Candel, M. J. J. M. and Meulenberg, M. T. G. (2003). The influence of the image of a product's region of origin on product evaluation. Journal of Business Research, 56, 215-226.

Van Vliet, V. (2011). Marketing mix, the 4P's (McCarthy). Retrieved 22 July 2019 from toolshero: https://www.toolshero.com//marketing/marketing-mix-4p-mccarthy/

Wansink, B., Painter, J., and Ittersum, K. (2001). Descriptive Menu Labels' Effect on Sales. Cornell Hospitality Quarterly, 42(6), 68-72.

Wansink, B., Ittersum, K., and Painter, J. (2005). How descriptive food names bias sensory perceptions in restaurants. Food Quality and Preference, 16, 393-400.

Warawudhi, R. and Praditwiengkham, W. (2017). Thai EFL Learners' Writing Styles via Corpus Driven Approach. Proceeding of the $6^{\text {th }}$ International Conference on Language, Education, Humanities and Innovation, 176-187.

Watcharakaweesilp, W. (2013). Collocations Used in English for Business Communication. Humanities and Social Sciences, 30(3), 53-80.

Yang, S.S., Kimes, S.E., and Sessarego, M.M. (2009). Menu price presentation influences on consumer purchase behavior in restaurants. International Journal of Hospitality Management, 28, $157-160$.

Yang, J. and Lee, J. (2019). Application of Sensory Descriptive Analysis and Consumer Studies to Investigate Traditional and Authentic Foods: A Review. Foods, 8(2), 54.

Zhong, Y. and Moon, H.C. (2020). What Drives Customer Satisfaction, Loyalty, and Happiness in Fast-Food Restaurants in China? Perceived Price, Service Quality, Food Quality, Physical Environment Quality, and the Moderating Role of Gender. Foods, 9(4), 460.

\section{AUTHOR BIODATA}

Piyada Low works as an assistant professor at the Faculty of Management Sciences, Kasetsart University Sriracha Campus, Thailand. 